\title{
Violência contra à mulher: avaliação do jogo "caixa de pandora" como ferramenta de aprendizagem
}

\author{
Mariana Nunes Montenegro', \\ Pollyana Araújo da Silva², \\ Jackeline Abílio de Souza ${ }^{3}$, \\ Ana Tereza de Medeiros ${ }^{4}$, \\ Liliane dos Santos Machado ${ }^{5}$, \\ Luana Rodrigues de Almeida ${ }^{6}$
}

\section{RESUMO}

Objetivou-se avaliar as potencialidades de um jogo de computador, Caixa de Pandora, como ferramenta de apoio ao aprendizado de estudantes de enfermagem sobre o tema da violência contra a mulher. Trata-se de uma pesquisa quantitativa, realizada com 62 estudantes do curso de enfermagem de uma Instituição de Ensino Superior. Foi aplicado um questionário para analisar a abordagem ao problema da violência e o impacto do game no processo ensino-aprendizado. Analisou-se as respostas sobre o impacto do jogo e sua aceitação através da estatística descritiva. Os resultados mostraram que o jogo motivou a reflexão e favoreceu a construção de novos conhecimentos e a aprendizagem do público alvo. Conclui-se que o jogo se apresentou como uma ferramenta potente para ser utilizada no processo de ensino e formação de estudantes de saúde, especificamente os da enfermagem, sobre o tema da violência.

Descritores: Violência Contra a Mulher; Educação em Enfermagem; Jogos de Vídeo.

\footnotetext{
${ }^{1}$ Enfermeira. João Pessoa, PB, Brasil. E-mail: mariananunesmontenegro@gmail.com.

2 Enfermeira. João Pessoa, PB, Brasil. E-mail: polly bustamante@hotmail.com.

${ }^{3}$ Enfermeira, Mestre em Modelos de Decisão e Saúde. Discente do Programa de Pós-Graduação em Modelos de Decisão e Saúde, nível Doutorado, da Universidade Federal da Paraíba. João Pessoa, PB, Brasil. E-mail: jackabilio@yahoo.com.br.

${ }^{4}$ Enfermeira, Doutora em Enfermagem. Professora Titular da Universidade Federal da Paraíba. João Pessoa, PB, Brasil. E-mail: anaterezaprof@gmail.com.

${ }^{5}$ Cientista da Computação, Doutora em Engenharia Elétrica. Professora Associada da Universidade Federal da Paraíba. João Pessoa, PB, Brasil. Email: liliane@di.ufpb.br.

${ }^{6}$ Enfermeira, Doutora em Modelos de Decisão e Saúde. Professora Adjunta da Universidade Federal da Paraíba. João Pessoa, PB, Brasil. E-mail: luanaralmeida02@gmail.com.
}

\section{Como citar esse artigo:}

Montenegro MN, Silva PA, Souza JA, Medeiros AT, Machado LS, Almeida LR. Violência contra à mulher: avaliação do jogo "caixa de pandora" como ferramenta de aprendizagem. Rev. Eletr. Enf. [Internet]. 2018 [acesso em: ];20:v20a53. Disponível em: https://doi.org/10.5216/ree.v20.54108. 


\section{INTRODUÇÃO}

A construção dos papéis de gênero, que define características sociais para o sexo masculino e o sexo feminino, tem naturalizado a opressão e as iniquidades sociais entre mulheres e homens ao longo de séculos, fazendo com que as primeiras sempre exerçam um papel de apoio e de submissão em relação aos segundos ${ }^{(1)}$.

Como um exemplo dessa relação hierárquica, a divisão social do trabalho tem reservado ao mundo feminino as tarefas domésticas, o cuidado dos filhos, entre outros deveres, enquanto que aos homens têm determinado a inserção no espaço público, bem como a tarefa de provedor e de protetor do $\operatorname{lar}^{(1)}$.

Neste contexto, situa-se a visão idealista de família patriarcalista, na qual as mulheres se tornam objetos de um contrato invisível entre homens. Esse contrato transforma as diferenças biológicas em sociais, tendo uma face de liberdade e a outra de sujeição, acarretando desigualdades de direitos e a violência contra o gênero feminino(2).

A violência contra mulher foi reconhecida como um assunto judicial e de segurança pública e, desde a década de 1990, tem sido considerada um grave problema mundial de saúde ${ }^{(3)}$. Entre os anos de 1980 e 2013, houve uma taxa de crescimento na mortalidade de mulheres por violência, passando de 1.353 óbitos, no ano de 1980, para 4.762 óbitos, em $2013^{(4)}$.

Nesse período, a legislação avançou no sentido de combater a impunidade e garantir a proteção e os direitos das mulheres violentadas, culminando com a sanção, em 2006, da Lei no 11.340, conhecida como Lei Maria da Penha, que tem o objetivo de punir e coibir crimes de violência contra a mulher. Pesquisas têm revelado que, após a lei entrar em vigor, o número de homicídios femininos diminuiu cerca de 7,6\% ao ano, alcançando resultados notoriamente positivos ${ }^{(4)}$.

Diante da dimensão do fenômeno, o tema da violência contra mulher ganhou destaque e tem sido discutido mundialmente, principalmente no que se refere à necessidade de seu enfrentamento por meio de ações de prevenção e de combate ao problema ${ }^{(1-4)}$.

Nessa perspectiva, ressalta-se a necessidade de construir e efetivar uma rede de serviços de apoio às mulheres em situação de violência. Para tanto, é pertinente qualificar os agentes dessa rede ${ }^{(1-4)}$. Por esse motivo, destaca-se o processo de formação de profissionais, especialmente os profissionais da saúde, para atuar nesses serviços, tendo em vista que, com muita frequência, são os primeiros, se não os únicos, buscados pelas mulheres, constituindo, muitas vezes, a porta de entrada para intervir no problema que ainda é desafiador e percorre os serviços públicos da rede de atenção à saúde ${ }^{(1-4)}$.

Considerando o processo de formação profissional, pode-se afirmar que, por terem acelerado e contribuído para a denúncia de casos de agressão, os meios de comunicação e as tecnologias passaram a constituir ferramentas importantes para o ensino, tornando-se grandes aliadas à promoção da visibilidade do fenômeno da violência contra a mulher ${ }^{(1)}$.

Uma estratégia que tem merecido destaque no âmbito do ensino e da formação são os jogos digitais. No que se refere às ferramentas educacionais tecnológicas, como os jogos, as vantagens mais apontadas na literatura são: oferecer ao usuário fácil compreensão do assunto abordado; possibilitar repetição sem demandar custos ou tempo; ser interessante e atrativo devido às suas peculiaridades gráficas; além de respeitar o ritmo de aprendizagem do jogador ${ }^{(5)}$. 
Considerando os pontos positivos apontados, a presente pesquisa utilizou o jogo de computador denominado de Caixa de Pandora para abordar a temática da violência contra a mulher. O jogo traz a história da vida de uma mulher em situação de violência doméstica que recorre aos serviços públicos de saúde em busca de cuidado, apoio e acolhimento às suas necessidades de saúde. Trata-se de um serious games ou "jogos sérios", pois aborda, de uma forma dinâmica e atrativa, assuntos de grande relevância, sendo, portanto, classificado como um jogo com propósito que vai além do entretenimento(6).

Aquele jogo foi, originalmente, destinado à educação de profissionais da saúde sobre questões de gênero, sendo utilizado nos processos de Educação Permanente para qualificação das práticas, como também, para avaliar o grau de aprendizado e de conhecimento que esses profissionais já tinham em seu exercício. Caixa de Pandora aborda o problema da violência contra a mulher com ênfase nos aspectos afetivos do processo de aprendizagem promovendo a motivação à reflexão e a consequente mudança de postura em relação ao tema abordado(6).

Considerando as possibilidades do uso de estratégias lúdicas para o aprendizado e diante das características do Caixa de Pandora, este estudo objetivou avaliar as potencialidades de um jogo de computador, o serious game Caixa de Pandora, como ferramenta de apoio ao aprendizado de estudantes de enfermagem sobre o tema da violência contra a mulher.

\section{MÉTODOS}

O presente estudo teve abordagem quantitativa de caráter descritivo. $O$ tipo de estudo quantitativo pode ser utilizado em pesquisas com enfoque objetivo, cujas análises podem envolver o auxílio de instrumentos padronizados e neutros e linguagem matemática para delinear as causas de um fenômeno estudado $0^{(7)}$.

Os dados desta pesquisa foram obtidos na Universidade Federal da Paraíba, Campus I, localizado em João Pessoa/PB, com estudantes do curso de Enfermagem, do Centro de Ciências da Saúde, entre os meses de julho e agosto de 2016 e que já tivessem cursado as disciplinas de Saúde da Mulher I e II, e ainda, que manifestaram concordância em participar.

De acordo com informações obtidas na Coordenação do Curso de Enfermagem, estimou-se que a população de interesse, no período da coleta de dados, seria de aproximadamente 130 estudantes. Diante desse quantitativo e considerando o cálculo para obtenção de uma amostra aleatória simples, o erro amostral de $5 \%$ e o nível de confiança de $95 \%$, a amostra consistiu em 98 elementos. Entretanto, excluindo as perdas obtidas no processo de coleta de dados - aproximadamente 30 estudantes - e em virtude da dificuldade de acesso aos graduandos por estarem em estágios finais do curso ocorridos fora do campus universitário, a amostra desta investigação foi composta por 62 participantes que cursavam o 7으, o 8ㅇ, o 9ㅇ e o 10 período letivo.

Foram incluídos na amostra os estudantes que atenderam aos seguintes critérios de inclusão: a) estar regularmente matriculado no curso de Bacharelado e Licenciatura em Enfermagem da UFPB; b) já ter cursado as disciplinas de Saúde da Mulher I e Il; e c) atender aos princípios éticos de apresentar interesse na participação do estudo, assinando o Termo de Consentimento Livre e Esclarecido.

A fim de atender ao objetivo desta pesquisa, os sujeitos do estudo tiveram acesso ao jogo e, subsequentemente, responderam a um questionário. Durante a coleta de dados, realizada no período de julho a agosto de 2016, os estudantes jogaram individualmente e, posteriormente, responderam ao questionário. 0 
levantamento foi realizado durante os intervalos das aulas ou durante as aulas mediante autorização prévia dos(as) professores(as). Os estudantes eram convidados a participar da pesquisa e, quando concordavam, o pesquisador fornecia um computador, onde o jogo encontrava-se instalado, ou convidava os participantes a se direcionarem para o laboratório de informática no qual o jogo também já tinha sido previamente instalado nos computadores. $\mathrm{O}$ jogo Caixa de Pandora está disponível para plataforma Windows, para execução na plataforma computador (PC) e pode ser acessado, por download, na página do laboratório de pesquisa que o projetou.

O questionário, instrumento da pesquisa, continha itens para a caracterização dos sujeitos da pesquisa (sexo, idade, situação conjugal, tempo de formação acadêmica, entre outros); indagava sobre o contato prévio dos alunos com o tema da violência contra a mulher e o modo como eles avaliavam a abordagem utilizada. Buscava também verificar a aceitação do jogo Caixa de Pandora entre os estudantes de enfermagem e avaliar as potencialidades do game como uma ferramenta de apoio ao processo de aprendizado sobre a temática da violência. Foram investigados quatro aspectos relacionados ao jogo: sua jogabilidade, em relação a sua facilidade de acesso de manuseio para o jogador; aparência (layout), no que se trata aos desenhos do jogo e apresentação gráfica e importância da estratégia, como a relevância do tema abordado.

O questionário utilizado foi adaptado da pesquisa de validação do jogo com os profissionais de saúde ${ }^{(6)}$. Para tanto, houve uma adequação ao novo público alvo, os estudantes de enfermagem, e aos objetivos traçados para este estudo. As respostas foram registradas em planilha do Excel e as frequências absolutas analisadas por meio da estatística descritiva.

A pesquisa foi submetida ao Comitê de Ética em Pesquisa com Seres Humanos do Centro de Ciência da Saúde - UFPB e obteve aprovação para sua execução de acordo com o CAAE no 55979416.0.0000.5188. Durante a realização da investigação, os participantes foram informados sobre o objetivo do estudo, a justificativa, a contribuição, a fidedignidade na análise das informações e a garantia do anonimato, bem como sobre o direito à liberdade de retirar-se da pesquisa a qualquer momento, se assim o desejassem, mesmo após terem assinado o Termo de Consentimento Livre e Esclarecido.

\section{RESULTADOS}

A análise descritiva do perfil dos jogadores demonstrou que os participantes tinham idades entre 20 e 30 anos, cursavam do sétimo ao décimo período e eram, na maioria dos casos, do sexo feminino e do nono e décimo períodos.

Sobre o contato prévio dos participantes com o tema da violência contra a mulher durante a graduação (Gráfico 1), a maioria afirmou que o tema foi abordado, de forma direta ou indireta, durante o curso. Dentre esses estudantes, a maior parcela afirmou que o estudo/discussão do tema ocorreu durante aulas expositivas. De acordo com a ementa da disciplina de Saúde da Mulher I, parte de sua carga horária é destinada àquela temática, quando os graduandos têm a oportunidade de abordá-la. Os demais participantes da pesquisa tiveram a oportunidade de discutir a temática por meio de filmes ou documentários ou participando de projeto de extensão com enfoque no tema da violência contra mulher. Ainda sobre a abordagem do tema na graduação, a maior parte dos estudantes considerou ter sido "satisfatória" ou "totalmente satisfatória". 
Gráfico 1: Aspectos Gerais sobre o Tema dos graduandos de enfermagem da Universidade Federal da Paraíba, Brasil, 2016.

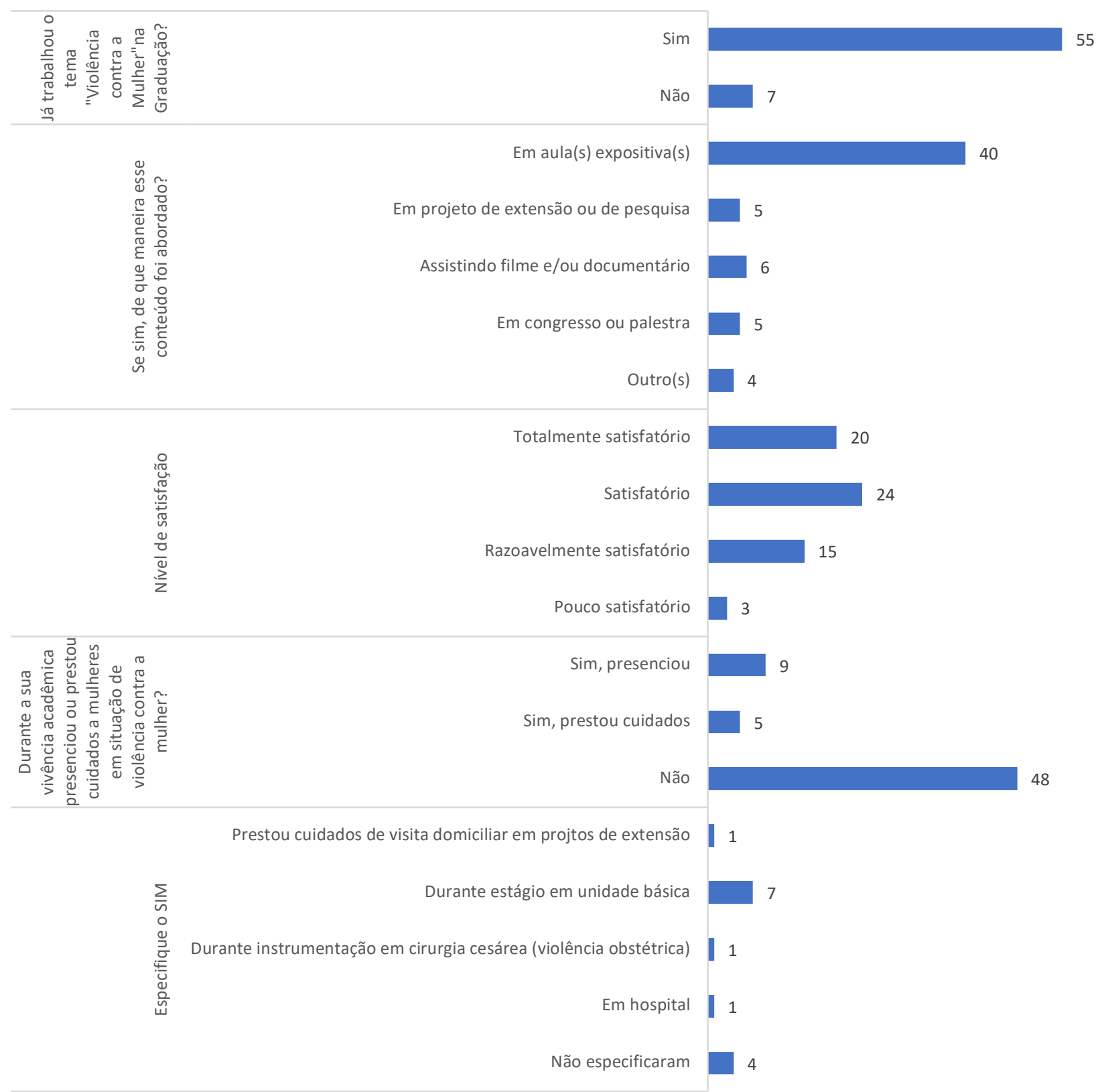

No âmbito das experiências práticas com situações de violência, a maioria dos participantes não chegou a ter a oportunidade de prestar assistência às mulheres em situação de violência ou a presenciar casos de violência durante o período acadêmico. A pequena parcela que relatou ter presenciado alguma situação de violência ou ter prestado cuidados à mulher nessa condição, afirmou que o cuidado prestado ocorreu através de consulta de enfermagem na Atenção Básica.

Sobre o jogo em foco, as respostas sinalizaram boa aceitação do aplicativo pelos estudantes. Os principais motivos para a maioria ter gostado de Caixa de Pandora foram porque ele aborda um tema complexo de uma forma didática, possui uma linguagem fácil e é dinâmico e lúdico, possibilitando ao jogador refletir sobre o tema. Quase $100 \%$ dos participantes concordaram sobre a qualidade do serious game, o classificando como "muito bom" ou "bom", e a maior parcela dos estudantes se sentiu motivada para jogar. 
No que tange ao grau de interesse ao assunto abordado pelo Caixa de Pandora (Gráfico 2), quase todos os estudantes o reconhecerem como "muito interessante" e o consideraram como "muito importante" para sua futura atuação profissional. Ademais, mais da metade dos participantes consideraram a estória apresentada no jogo "muito interessante", assim como, para a maioria dos estudantes, o Caixa de Pandora contribuiu para a compreensão do fenômeno da violência contra mulheres. A aprendizagem de novos conceitos foi apontada pela maioria dos estudantes, cujos temas mais frequentemente apreendidos foram sobre legislação, atuação profissional e serviços de apoio às mulheres.

Gráfico 2: Impressões do jogador e aprendizado dos graduandos de enfermagem da Universidade Federal da Paraíba, Brasil, 2016.

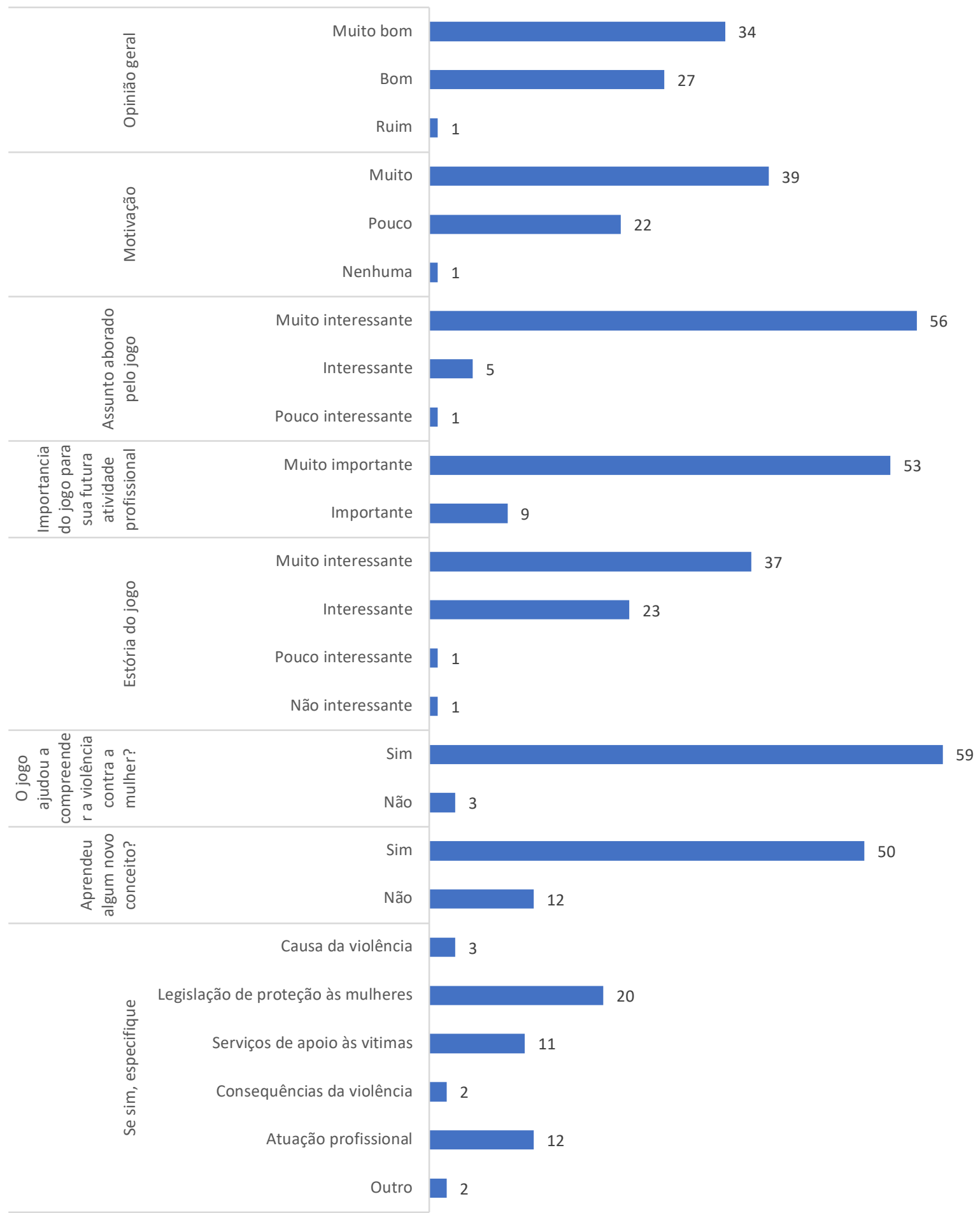


Quanto aos aspectos relativos a jogabilidade, a maior parcela dos estudantes considerou o jogo muito fácil e fácil, não tendo dificuldades para utilizar o aplicativo. Esses resultados também se repetiram em relação ao grau de dificuldade das perguntas e respostas, em que quase todos consideraram fáceis e compreensíveis. Já quanto à passagem "automática" de cenas, mais da metade afirmou ter gostado, ao passo que uma parcela pouco menor considerou que gostaria que tivesse a opção de controlar essas transições (Gráfico 3).

Gráfico 3: Opinião geral sobre o jogo dos graduandos de enfermagem da Universidade Federal da Paraíba, Brasil, 2016.

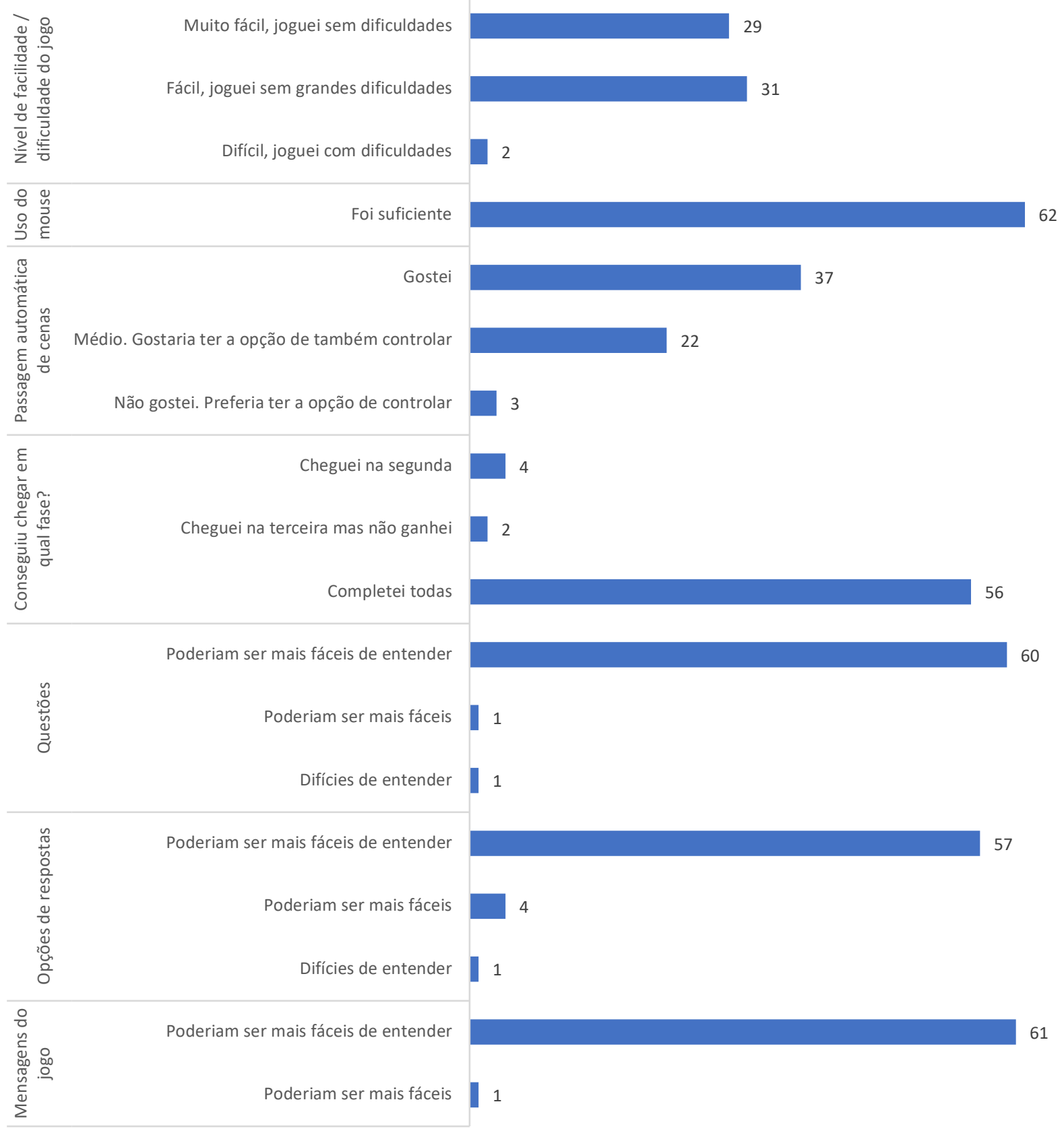

\section{DISCUSSÃO}

No curso de Graduação em Enfermagem, na instituição cenário de estudo, o tema, violência contra a mulher, é abordado na disciplina de Saúde da Mulher em duas aulas expositivas, como temática curricular obrigatória. Sobre a inclusão desse assunto nos currículos dos cursos de saúde, assumir essa temática enquanto 
obrigatória em algumas disciplinas significa dar-Ihe a devida importância, priorizá-la na formação dos alunos, além de ser uma forma de motivar os docentes para que busquem qualificação(8).

Apesar de a abordagem do tema na graduação ter sido considerada como uma experiência satisfatória pelos graduandos, muitos autores discutem a falta de aprofundamento sobre o tema nos currículos dos cursos de Graduação em Saúde. Abordagens superficiais, incipientes e a predominância da discussão centrada no modelo biomédico, são grandes entraves na formação do profissional| ${ }^{(8-11)}$, prejudicando a futura atuação de muitos estudantes, que, enquanto profissionais, lidarão diariamente com situações de violência. Esses profissionais, pela posição que ocupam na prestação de serviços à população, são considerados estratégicos para a identificação de vulnerabilidade e/ou ocorrência da violência ${ }^{(9)}$.

Alguns participantes do estudo afirmaram que, ainda na graduação, durante os estágios, já tinham prestado assistência à mulher em situação de violência ou já tinham presenciado alguma situação de violência. Logo no primeiro ano do curso, os estudantes desempenham atividades práticas em Unidades Básicas de Saúde, onde aproximam-se da comunidade e buscam intervir nas necessidades de saúde daquela população, seja por meio de ações de educação em saúde ou por meio de intervenção clínica supervisionada pelo tutor/docente. Essa aproximação precoce com o serviço de saúde viabiliza o contato com inúmeras situações de vulnerabilidade, inclusive com casos de violência contra a mulher. $O$ fato de já terem vivenciado situações dessa natureza, ainda no curso de graduação, anuncia aos discentes o que eles poderão enfrentar em sua rotina profissional, os preparando para situações futuras quando atuarão como profissionais do serviço e não mais como estudantes ${ }^{(8-}$ 10).

Na contramão do que foi anteriormente exposto, após formados, muitos profissionais da saúde têm dificuldade para abordar a mulher, usuária do serviço onde atuam, que, possivelmente, esteja sofrendo violência $^{(10-14)}$. Nesse contexto, autores explicam que os principais problemas que contribuem para a invisibilidade desse tipo de violência são a redução do problema ao plano biológico e a ausência do tema da violência de gênero, raça/etnia e classe social nos currículos da academia. Além disso, muitas vezes, a prática profissional é orientada por concepções e saberes que reproduzem estereótipos de gênero de culpabilização da vítima, fazendo com que, embora o tema tenha sido discutido durante a formação, a abordagem não apresente potencialidades para reorientar o processo de trabalho em saúde.

A necessidade de se trabalhar o tema com mais eficácia, ainda na graduação - fazendo uso de metodologias ativas, que estimulem a reflexão e a construção de novos saberes, como por exemplo, o uso de serious games -, está presente em diversas áreas, uma vez que os dados comprovam que a violência de gênero está sendo subnotificada, ocultada ou não documentada. Na maioria dos cursos, o tema ou é pouco abordado ou, nem sequer, é trabalhado. Muitos professores não concordam com a existência de uma disciplina que aborde exclusivamente o tema "violência", considerando que ele pode ser abordado de forma transversal às disciplinas. Nesse sentido, alerta-se para o risco de que a incorporação desse tema de forma não obrigatória possa favorecer a sua invisibilidade e a sua subestimação(8-10).

No que se refere ao jogo, além de ser bem aceito e motivar os estudantes a aprenderem sobre a temática, a maior parte dos participantes afirmou que gostou do jogo, que se sentiu motivado a jogar e reconheceu a relevância do tema abordado. Isso indica o potencial do uso de novas metodologias para o ensino aprendizagem, 
particularmente o uso de serious games, tendo em vista que permite abordar de maneira lúdica temas já trabalhados na graduação, tornando o assunto atrativo, motivando a reflexão e contribuindo para a percepção de que se pode aprender mais sobre o assunto ${ }^{(12-14)}$.

Com o avanço da tecnologia nas duas últimas décadas, novos sistemas e equipamentos têm surgido de forma a favorecer processos educacionais. Os serious games podem possibilitar aos estudantes refletir, mesmo que em uma situação fictícia, simulatória, elementos que, enquanto profissionais de enfermagem, irão se deparar em um futuro. Tal potencialidade é característica desses jogos, desenvolvidos com o propósito de unir aspectos lúdicos a conteúdos específicos ${ }^{(10-14)}$.

Os jogos colocam o estudante no papel de tomador de decisão, papel que o enfermeiro exercerá, principalmente, ao se deparar com situações de violência. Nesse aspecto, é necessário que essa capacidade de tomar decisão comece a ser desenvolvida ainda na graduação, uma vez que nessa fase os estudantes vivenciam situações simuladas e seus erros estarão limitados ao mundo virtual(6).

Os achados desta pesquisa são semelhantes ao de outro estudo realizado com profissionais da saúde que avaliaram o mesmo jogo. No estudo, evidenciou-se que, assim como aconteceu com os estudantes, quase todos os profissionais reconheceram que Caixa de Pandora favoreceu a construção de novos conhecimentos no que se refere à atuação profissional ${ }^{(6)}$.

A maioria dos estudantes afirmou que o jogo era muito fácil e abordava uma problemática complexa de forma didática e lúdica, possibilitando ao jogador refletir sobre o tema e aprender novos conceitos. As impressões dos estudantes sobre o jogo concordaram com as percepções dos profissionais, que reconheceram o impacto do jogo nas motivações para a reflexão e a tomada de consciência no sentido de uma mudança de concepções e práticas ${ }^{(6)}$. Essa potencialidade dos jogos de vídeo com propósito decorre dos seus elementos lúdicos, uma vez que os jogos digitais proporcionam uma experiência estética visual e espacial rica e, com isso, são capazes de atrair os jogadores para dentro de mundos fictícios que podem simular situações reais, despertando sentimentos e reflexões ${ }^{(6)}$.

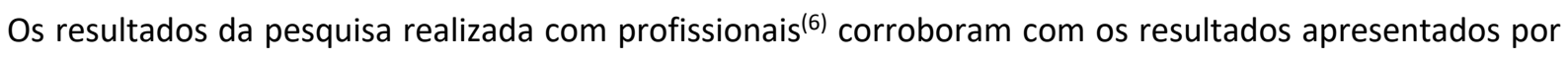
esta pesquisa, no sentido de que o jogo teve uma boa aceitação pelos participantes que jogaram sem grandes dificuldades. Essa observação indica mais um ponto positivo do serious game, a facilidade de ser utilizado como uma estratégia de ensino, auxiliando as técnicas tradicionais.

Quando se trata de um tema com tantos estereótipos, que envolve concepções socioculturais e crenças tão cristalizadas, como é o caso da violência, é preciso que ele seja abordado de forma mais lúdica e leve, buscando alcançar aspectos afetivos da aprendizagem no que se refere ao respeito, à valorização e outros afetos humanos. Essas características contribuem para a formação de um futuro profissional de saúde mais empático, conhecedor das estratégias de prevenção e de promoção da saúde da mulher, a fim de que desempenhe práticas com potencial para a emancipação da opressão de gênero(6).

\section{CONSIDERAÇÕES FINAIS}

O tema da violência contra a mulher requer uma abordagem ampla e complexa devido às suas proporções mundiais e impactos que provocam na vida e saúde das mulheres. Não se trata apenas de cuidar dos sintomas da 
violência, mas sim, investigar a sua raiz. Nesse contexto, verifica-se a necessidade de trabalhar o tema no âmbito da graduação, por meio de metodologias que motivem a reflexão por parte dos futuros profissionais que, possivelmente, se depararão com situações de violência em suas práticas.

O serious game Caixa de Pandora, avaliado por estudantes de enfermagem, foi bem aceito pelo público alvo desta pesquisa enquanto uma estratégia inovadora de ensino que proporcionou a construção de novos conhecimentos e motivou a reflexão sobre a temática, complementando a experiência prévia dos alunos, mostrando-se como uma excelente ferramenta de aprendizagem, principalmente no que se refere ao conhecimento da Lei Maria da Penha. Foi mencionado também a possibilidade de autorreflexão proporcionada pelo jogo no que tange à postura do profissional de Enfermagem diante de uma situação de violência.

As limitações deste estudo se deram por conta da dificuldade do acesso aos estudantes que, por estarem em fase de conclusão do curso, encontravam-se em estágios fora da faculdade. Além disso, alguns não aceitaram participar da pesquisa por conta do tempo dispensado para jogar e alguns questionários foram perdidos por terem sido respondido parcialmente ou por não terem concluído o jogo.

Atualmente, uma nova versão do jogo Caixa de Pandora está sendo desenvolvida, a partir de um processo de redesign, de modo a adequar a linguagem para uso do público geral (maior de 13 anos) em smartphones com o sistema Android. Esse projeto amplia as possibilidades de acesso e uso do aplicativo, favorecendo estudos futuros de avaliação das potencialidades do jogo.

\section{REFERÊNCIAS}

1. Fonseca RMGS, Santos DLA, Gessner R, Fornari LF, Oliveira RNG, Schoenmaker MC. Gender, sexuality and violence: perception of mobilized adolescents in an online game. Rev Bras Enferm [Internet]. 2018 [cited 2018 Dec 31];71 (suppl 1):607-14. Available from: https://doi.org/10.1590/0034-7167-2017-0561.

2. Zanatta MA, Faria JP. Violência contra a mulher e desigualdade de gênero na estrutura da sociedade: da superação dos signos pela ótica das relações de poder. Revista de Gênero, Sexualidade e Direito [Internet]. 2018 [cited 2018 Dec 31];4(1):99-114.

Available from: https://doi.org/10.26668/2525-9849/Index Law Journals/2018.v4i1.4209.

3. Almeida LR, Silva ATMC, Machado LS. Jogos para capacitação de profissionais de saúde na atenção à violência de gênero. Rev Bras Educ Med [Internet]. 2013 [cited 2018 Dec 31];37(1):110-9. Available from: https://doi.org/10.1590/S0100-

55022013000100016.

4. Waiselfisz JJ. Mapa da violência: homicídio de mulheres no Brasil [Internet]. 1ạ ed. Brasília: Flacso; 2015 [cited 2018 Dec 31 ]. Available from: https://www.mapadaviolencia.org.br/pdf2015/MapaViolencia 2015 mulheres.pdf.

5. Shaikh F, Inayat F, Awan O, Santos MD, Choudhry AM, Waheed A, et al. Computer-Assisted Learning Applications in Health Educational Informatics: A Review. Cureus [Internet]. 2017 [cited 2018 Dec 31];9(8):e1559. Available from:

https://www.cureus.com/articles/8349-computer-assisted-learning-applications-in-health-educational-informatics-a-review. 6. Almeida LR, Machado LS, Medeiros AT, Coelho HFC, Andrade JM, Moraes RM. The Caixa de Pandora Game. Comput Entertain [Internet]. 2018 Sep 12;16(3):Article 2. Available from: https://doi.org/10.1145/3236493.

7. Polit DF, Beck CT, Beck CT. Fundamentos de pesquisa em enfermagem: avaliação de evidencias para a pratica da enfermagem. $9 \underline{a}$ ed. Porto Alegre: Artmed; 2018.

8. Rigol-Cuadra A, Galbany-Estragué P, Fuentes-Pumarola C, Burjales-Martí MD, Rodríguez-Martín D, Ballester-Ferrando D. Perception of nursing students about couples' violence: knowledge, beliefs and professional role. Rev Lat Am Enfermagem [Internet]. 2015 [cited 2018 Dec 31];23(3):527-34. Available from: https://doi.org/10.1590/0104-1169.0357.2584.

9. Cordeiro KCC, Santos RM, Gomes NP, Melo DS, Mota RS, Couto TM. Formação profissional e notificação da violência contra a mulher. Revista Baiana de Enfermagem [Internet]. 2015 [cited 2018 Dec 31];29(3):209-17. Available from:

https://doi.org/10.18471/rbe.v29i3.13029.

10. Zanatta EA, Schneider AC, Kloh D, Vendruscolo C, Krüger JH, Hermes TC, et al. Violência no âmbito da formação em saúde: estudo bibliométrico. Revista Saúde - UNG-SER [Internet]. 2015 [cited 2018 Dec 31];9(3-4):81-92. Available from:

http://revistas.ung.br/index.php/saude/article/view/2142. 
11. Lettiere A, Nakano AMS. Rede de atenção à mulher em situação de violência: os desafios da transversalidade do cuidado. Rev. Eletr. Enf. [Internet] 2015 [cited 2018 Dec 31];42(3). Disponível em: https://doi.org/10.5216/ree.v17i4.32977.

12. Brum CRS, Lourenço LM, Gebara CFP, Ronzani TM. Violência Doméstica e Crenças: Intervenção com Profissionais da Atenção Primária à Saúde. Psicologia em Pesquisa [Internet]. 2013 [cited 2018 Dec 31];7(2):242-50. Available from:

https://doi.org/10.5327/Z1982-1247201300020012.

13. Santos CA, Souza-Junior VD, Lanza FF, Lacerda AJ, Jorge BM, Mendes IAC. Jogos sérios em ambiente virtual para ensinoaprendizagem na saúde. Rev Rene [Internet]. 2017 [cited 2018 Dec 31];18(5):702-9. Available from:

http://www.periodicos.ufc.br/rene/article/view/30851.

14. White EJ, Lewis JH, McCoy L. Gaming science innovations to integrate health systems science into medical education and practice. Adv Med Educ Pract [Internet]. 2018 [cited 2018 Dec 31]2018(9):407-14. Available from:

https://doi.org/10.2147/AMEP.S137760. 